\title{
Editorial \\ Coordination Polymers and Metal-Organic Frameworks: Structures and Applications-A Themed Issue in Honor of Professor Christoph Janiak on the Occasion of His 60th Birthday
}

\author{
Catherine E. Housecroft (D)
}

check for updates

Citation: Housecroft, C.E.

Coordination Polymers and Metal-Organic Frameworks: Structures and Applications-A Themed Issue in Honor of Professor Christoph Janiak on the Occasion of His 60th Birthday. Chemistry 2021, 3, 831-833. https://doi.org/ 10.3390/chemistry3030060

Received: 14 July 2021

Accepted: 27 July 2021

Published: 28 July 2021

Publisher's Note: MDPI stays neutral with regard to jurisdictional claims in published maps and institutional affiliations.

Copyright: (C) 2021 by the author. Licensee MDPI, Basel, Switzerland. This article is an open access article distributed under the terms and conditions of the Creative Commons Attribution (CC BY) license (https:/ / creativecommons.org/licenses/by/ $4.0 /)$.
Department of Chemistry, University of Basel, Mattenstrasse 24a, BPR 1096, 4058 Basel, Switzerland; catherine.housecroft@unibas.ch

This themed issue of Chemistry is in honor of Professor Christoph Janiak on the occasion of his 60th birthday, and celebrates his innovative contributions to the fields of supramolecular chemistry, coordination polymers, networks and metal-organic frameworks, inorganic/organic hybrid materials and inorganic materials from ionic liquids.

Professor Janiak currently holds a chair in Bioinorganic Chemistry and Catalysis at the Heinrich Heine University of Düsseldorf and his research interests span metal-organic frameworks (MOFs), coordination polymers, chirality, supramolecular interactions and metal nanoparticles in ionic liquids. Two of his seminal reviews have influenced many of us working in the fields of heterocyclic chemistry and coordination networks: "A critical account on $\pi-\pi$ stacking in metal complexes with aromatic nitrogen-containing ligands" (Dalton Trans. 2000, 3885) and "Engineering coordination polymers towards applications" (Dalton Trans. 2003, 2781), which have been cited close to 6000 times.

The issue begins with a preface written by Spyros Perlepes, which provides a personalized account of the achievements of Christoph Janiak. This sets the scene for many of the topics covered in the eleven contributions described in this editorial.

Baca and Kögerler have contributed a review dealing with cluster-based coordination polymers in which the clusters act as nodes in the assemblies. The focus is on recent developments in architectures containing $\mathrm{Mn} / \mathrm{Fe}$-oxo pivalate and isobutyrate building blocks, and on the synthetic strategies and the magnetic behavior of these coordination polymers [1].

Carboxylate linkers are popular choices in the assembly of coordination polymers and networks, and therefore it is not surprising that these donors feature in several of the papers in this themed issue. The metal-organic framework UiO-66 is formed from $\mathrm{ZrCl}_{4}$ and terephthalic acid, and is a highly stable assembly. Yang, Schröder and coworkers have demonstrated the ability of a defective form of UiO-66 to take up $\mathrm{I}_{2}$, and this investigation is relevant to the uptake and storage of radioactive $\mathrm{I}_{2}$ [2]. Additionally related to adsorption of toxic small molecules (in this case $\mathrm{CS}_{2}$ ), Li and coworkers have described the conjugate bases of $4^{\prime}, 4^{\prime \prime \prime}, 4^{\prime \prime \prime \prime \prime}, 4^{\prime \prime \prime \prime \prime \prime \prime \prime \prime}$-(ethene-1,1,2,2-tetrayl)tetrakis(([1,1'-biphenyl]-4-carboxylic acid)), $\mathrm{H}_{4}$ tcbpe, and a tetrafluoro-derivative, $\mathrm{H}_{4} \mathrm{tcbpe}-\mathrm{f}$, which act as tetratopic ligands to assemble $\left[\mathrm{Zr}_{6}\left(\mu_{3}-\mathrm{O}\right)_{4}(\mathrm{OH})_{8}(\mathrm{tcbpe})_{2}\left(\mathrm{H}_{2} \mathrm{O}\right)_{4}\right]$ and $\left[\mathrm{Zr}_{6}\left(\mu_{3}-\mathrm{O}\right)_{4}(\mathrm{OH})_{8}(\text { tcbpe-f })_{2}\left(\mathrm{H}_{2} \mathrm{O}\right)_{4}\right]$; these assemblies are strongly luminescent and have been applied as fluorescent sensors for the detection of $\mathrm{CS}_{2}$ [3]. Chhetri, Chen and coworkers have detailed a series of coordination polymers constructed from copper(II) or cadmium(II) combined with semi-rigid $N, N^{\prime}$-bis(3pyridyl)terephthalamide and dicarboxylic acids; the assemblies encompass 1D, 2D and 3D architectures [4]. The chelidonate ligand has the potential to offer several different metal-binding modes. In their paper, Carballo et al. have combined chelidonic acid and either 4,4'-bipyridine or 1,2-bis(4-pyridyl)ethane with zinc(II) and copper(II) to give a series of coordination polymers in which the chelidonate dianion acts either as a non-coordinating counterion, or as a bridging ligand [5]. 
Linkers incorporating pyridine donors are also popular among coordination polymer chemists. The work by Carballo et al. [5] introduced these donors, and this is complemented by a report from Andruh, Avarvari and coworkers concerning the coordination behavior of three bis(pyridine) ligands containing benzothiadiazole spacers. Both discrete and polymeric assemblies are described with zinc(II) and silver(I) [6]. Two contributions focus on terpyridines. Harrowfield and coworkers provide a detailed analysis of the weak interactions in the single crystal structures of 33 metal(II) complexes incorporating twelve $4^{\prime}$-functionalized $2,2^{\prime}: 6^{\prime}, 2^{\prime \prime}$-terpyridine (tpy) ligands. The structural and packing details that are revealed in this investigation should be valuable in the future design of functional materials based on tpy [7]. While $2,2^{\prime}: 6^{\prime}, 2^{\prime \prime}$-terpyridine is the ubiquitous isomer of terpyridine, $3,2^{\prime}: 6^{\prime}, 3^{\prime \prime}$-terpyridine has been far less studied. We have contributed to this issue of Chemistry with an investigation of the effects of the conformational flexibility of $3,2^{\prime}: 6^{\prime}, 3^{\prime \prime}$-tpy (functionalized in the $4^{\prime}$-position with a biphenyl domain) on the structures and crystal packing of $1 \mathrm{D}$ coordination polymers bearing $\mathrm{Cu}_{2}(\mu-\mathrm{OAc})_{4}$ paddle-wheel units [8].

The final three contributions are focused either on the magnetic or electrochemical properties of arrays with different nuclearities or on organic donor-acceptor Stenhouse adducts, respectively. Cimpoesu, Ferbinteanu and coworkers describe a series of pyrazolato-bridged, multinuclear copper(II) coordination compounds; the magnetic properties of these $\mathrm{Cu}_{3}, \mathrm{Cu}_{6}$ and $\mathrm{Cu}_{7}$-containing species are dominated by the strong antiferromagnetism across the pyrazolate bridges [9]. Neville and coworkers have investigated the use of the $N$-(pyridin-4-yl)benzamide ligand in $\{\mathrm{Fe}(\mathrm{II}) \mathrm{Pd}(\mathrm{II})\}$ and $\{\mathrm{Fe}(\mathrm{II}) \mathrm{Pt}(\mathrm{II})\}$-containing 2D Hofmann-type frameworks to facilitate spin crossover cooperativity through hydrogen bonding involving the amide moiety [10]. A departure from the main theme of the issue comes with an investigation of donor-acceptor Stenhouse adducts. These represent a class of photoswitches that undergo light-initiated triene cyclization. However, D'Alessandro and coworkers have demonstrated that electrochemical oxidation is an effective alternative stimulus [11].

I would like to take this opportuniy to thank all the teams of researchers who have contributed to this issue, which is dedicated to Christoph Janiak. Together, we express our sincere good wishes on the occasion of Christoph's 60th birthday.

\section{References}

1. Baca, S.; Kögerler, P. Cluster-Based Coordination Polymers of Mn/Fe-Oxo Pivalates and Isobutyrates. Chemistry 2021, 3, 314-326. [CrossRef]

2. Maddock, J.; Kang, X.; Liu, L.; Han, B.; Yang, S.; Schröder, M. The Impact of STructural Defects on Iodine Adsorption in UiO-66. Chemistry 2021, 3, 525-531. [CrossRef]

3. Velasco, E.; Osumi, Y.; Teat, S.J.; Jensen, S.; Tan, K.; Thonhauser, T.; Li, J. Fluorescent Detection of Carbon Disulfide by a Highly Emissive and Robust Isoreticular Series of Zr-Based Luminescent Metal Organic Frameworks (LMOFs). Chemistry 2021, 3, 327-337. [CrossRef]

4. Chen, C.-J.; Chen, C.-L.; Liu, Y.-H.; Lee, W.-T.; Hu, J.-H.; Chhetri, P.M.; Chen, J.-D. Coordination Polymers Constructed from Semi-Rigid $N, N^{\prime}$-Bis(3-pyridyl)terephthalamide and Dicarboxylic Acids: Effect of Ligand Isomerism, Flexibility, and Identity. Chemistry 2021, 3, 1-12. [CrossRef]

5. Carballo, R.; Lago, A.B.; Pino-Cuevas, A.; Gómez-Paz, O.; Fernández-Hermida, N.; Vázquez-López, E.M. Neutral and Cationic Chelidonate Coordination Polymers with $N, N^{\prime}$-Bridging Ligands. Chemistry 2021, 3, 256-268. [CrossRef]

6. Mocanu, T.; Plyuta, N.; Cauchy, T.; Andruh, M.; Avarvari, N. Dimensionality Control in Crystalline Zinc(II) and Silver(I) Complexes with Ditopic Benzothiadiazole-Dipyridine Ligands. Chemistry 2021, 3, 269-287. [CrossRef]

7. Lee, Y.H.; Kim, J.Y.; Kusumoto, S.; Ohmagari, H.; Hasegawa, M.; Thuéry, P.; Harrowfield, J.; Hayami, S.; Kim, Y. Functionalised Terpyridines and Their Metal Complexes—Solid-State Interactions. Chemistry 2021, 3, 199-227. [CrossRef]

8. Rocco, D.; Novak, S.; Prescimone, A.; Constable, E.C.; Housecroft, C.E. Manipulating the Conformation of $3,2^{\prime}: 6^{\prime}, 3^{\prime \prime}$-Terpyridine in $\left[\mathrm{Cu}_{2}(\mu-\mathrm{OAc})_{4}\left(3,2^{\prime}: 6^{\prime}, 3^{\prime \prime} \text {-tpy }\right)\right]_{n}$ 1D-Polymers. Chemistry 2021, 3, 182-198. [CrossRef]

9. Toader, A.M.; Buta, M.C.; Cimpoesu, F.; Toma, A.-I.; Zalaru, C.M.; Cinteza, L.O.; Ferbinteanu, M. New Syntheses, Analytic Spin Hamiltonians, Structural and Computational Characterization for a Series of Tri-, Hexa- and Hepta-Nuclear Copper(II) Complexes with Prototypic Patterns. Chemistry 2021, 3, 411-439. [CrossRef] 
10. Ong, X.; Ahmed, M.; Xu, L.; Brennan, A.T.; Hua, C.; Zenere, K.A.; Xie, Z.; Kepert, C.J.; Powell, B.J.; Neville, S.M. Spin-Crossover 2-D Hofmann Frameworks Incorporating an Amide-Functionalized Ligand: N-(pyridin-4-yl)benzamide. Chemistry 2021, 3, 360-372. [CrossRef]

11. Shepherd, N.D.; Moore, H.S.; Beves, J.E.; D'Alessandro, D.M. Electrochemical Switching of First-Generation Donor-Acceptor Stenhouse Adducts (DASAs): An Alternative Stimulus for Triene Cyclisation. Chemistry 2021, 3, 728-733. [CrossRef] 